\title{
Sonhos que migram: atrizes e atores brasileiros em Nova York ${ }^{1}$
}

\author{
Bernardo Fonseca Machado \\ Doutorando na Universidade de São Paulo, Brasil \\ bernardofmachado@gmail.com \\ Lilia Moritz Schwarcz \\ Professora Doutora da Universidade de São Paulo, Brasil \\ lilia.ms@uol.com.br
}

Resumo Neste artigo trabalhamos com as narrativas de jovens de classe média brasileira que viajaram para Nova York, nos Estados Unidos, ao longo da segunda década do século XXI, com a intenção de se especializarem como artistas. Movidas/os por expectativas de imersão no mercado de entretenimento estadunidense, migraram com o sonho de tentar uma carreira no exterior. Estamos particularmente interessados em analisar a forma como esses sujeitos lidaram com o hiato entre as expectativas iniciais e as condições materiais experimentadas. Entre o plano de estrelato e sua realização, enfrentam um mercado competitivo, entraves burocráticos e a instantânea "racialização" de seus corpos - especialmente no caso das mulheres. Elegemos a noção de "quebra de expectativas" - suas consequências e efeitos - como objeto de análise, e procuramos inspiração no que se convencionou chamar de pesquisas "multissituadas", atentos que estamos como alegorias e sonhos que transitam entre cidades.

Palavras-chave: artistas, migração, Estados Unidos, sonhos, quebra de expectativa.

Processos migratórios costumam ser experimentados por sujeitos como eventos que instauram rupturas. Constituem-se como pontos de inflexão (no tempo, no espaço e nas ações) que produzem significados irreversíveis. No interior dessa trajetória, uma série de projeções povoam os imaginários dos sujeitos envolvidos, e constituem uma espécie de pavimento - ainda

1 Este artigo dá prosseguimento às reflexões apresentadas por Bernardo Fonseca Machado no $40^{\circ}$ Encontro Anual da ANPOCS de 2016 sob o nome "Brazilian Actresses" - gênero, "raça' e sexualidade de atrizes brasileiras nos EUA". Com novo material, também aprofundamos determinadas discussões já iniciadas e reformulamos outras. 
que movediço - para os passos que serão então tomados. Aí estão sonhos gestados na infância, desejos fomentados na adolescência, expectativas cultivadas aos poucos e que se transformam em poderosos combustíveis para a mudança. Contudo, ao pousarem na nova realidade social, esses mesmos personagens enfrentam desafios, deparando-se com problemas sequer formulados e precisam adequar suas práticas às novas condições.

Neste artigo, trabalhamos com as narrativas de jovens de classe média brasileira - a maioria proveniente da região sudeste do país - que viajaram para Nova York, nos Estados Unidos, com a firme intenção de se especializarem como atrizes e/ou atores. Movidas/ os por expectativas de imersão no mercado de entretenimento estadunidense, migraram no início da segunda década do século XXI para tentar uma carreira no exterior. Como primeiro passo, procuravam em geral o aprendizado - ingressando em cursos e faculdades especializados. No entanto, aos poucos, passaram a pleitear trabalho no competitivo mercado de artistas dos EUA.

Estamos particularmente interessados na análise de como esses sujeitos lidaram com o hiato entre as expectativas iniciais e as condições materiais experimentadas. Eleger essa questão permite acessar, simultaneamente, duas dimensões de suas experiências migratórias: de um lado, o imaginário que ronda artistas e alimenta sonhos de sucesso; de outro, as condições sociais, econômicas e legais enfrentadas diante desse novo cotidiano. Entre o plano de estrelato e sua realização, encontram um mercado competitivo, entraves burocráticos e a instantânea racialização de seus corpos - especialmente no caso das mulheres.

Ao eleger a noção de "quebra de expectativa" - suas consequências e efeitos como objeto de análise, procuramos encontrar uma alternativa teórica para lidar com oposição entre micro ou macro análises. A questão passa a ser: como repertórios de sucesso informam sujeitos em migração e quais seus impactos diante da realidade encontrada?

Para tanto, buscamos inspiração em pesquisas que procuram escapar da polarização entre o local e o global e exploram espaços “entre”. Durante os anos 1990 várias possibilidades teóricas foram formuladas visando lidar com esse tipo de problema. Nesse contexto, testemunhou-se uma grande proliferação de textos que pretendiam, por sua vez, dialogar com os novos eventos e circunstâncias que emergiam num mundo dito "globalizado". O suposto é que diante desse novo cenário, metodologias mais tradicionais da antropologia calcadas no modelo malinowskiano de "fazer etnográfico" e na concentração da pesquisa em um único local e em um dado período temporal - teriam se mostrado incapacitadas a estudar e entender fenômenos, como esses, em trânsito ${ }^{2}$. Desde os anos 1980 duas tradições têm apresentado formulações inéditas para esse tipo de problema: a chamada "teoria da prática" discutiu a relação entre sujeitos e estruturas e a crítica pós-moderna vem refletindo sobre as estabilizações tecidas pelas meta teorias ${ }^{3}$. Em 1995, o antropólogo estadunidense George Marcus elaborou um texto que, de um lado, fazia um balanço dos experimentos antropológicos realizados até aquele momento; de outro, sintetizava as soluções e os

2 Exemplos de textos decisivos dessa época são Appadurai (1996) e Strathern (1991).

3 Para saber mais sobre "teoria da prática", conferir Ortner (2011) e sobre a crítica à meta teorias, Marcus e Clifford (2016). 
rumos possíveis para próximas pesquisas. Marcus (1995) destacou dois modos de lidar com o trânsito entre escalas micro e macro na antropologia. Uma das estratégias consiste em explicar as práticas observadas localmente como situadas em macroteorias; ou seja, como exemplos do contexto. A outra estratégia, etnografa a "circulação" de atores, objetos e discursos nos múltiplos pontos do globo. A essa metodologia Marcus chamou de "etnografia multissituada"; um exercício de mapeamento analítico, cujo objetivo não é a representação holística, um retrato do sistema mundial em sua totalidade, mas o desenho de cadeias, caminhos, conjunções e justaposições. Distanciando-se de pesquisas singularmente situadas, a proposição permitiria seguir pessoas, coisas, metáforas, histórias (narrativas ou alegorias), biografias e conflitos. Vale lembrar, por exemplo, que estudos migratórios têm buscado assumir tal procedimento de análise, acompanhando um grupo particular de sujeitos.

Neste texto, em diálogo direto com as estimulantes formulações de Marcus, faremos o esforço de seguir não pessoas, mas sim, uma alegoria: o "sonho" de sucesso. Melhor dizendo, como tal narrativa está sendo mobilizada, atualizada e experimentada por esses/ as artistas. Importante salientar que, em suas falas, a cidade de Nova York aparece como sinônimo de prestígio na busca desse tipo de especialização profissional. E é justamente esse imaginário que anima tais sujeitos a tentar a saída via a migração. O objetivo é investigar como repertórios forjados em circunstâncias e localidades específicas passam a transitar de forma transnacional mobilizando sujeitos a agirem em diálogo com tais narrativas, sonhos e expectativas.

A escolha desses intérpretes como objeto privilegiado de análise não foi acidental. $\mathrm{Na}$ arte de representação, histórias e técnicas forjadas em locais, os mais variados, são atualizadas constantemente nos corpos de artistas. Ao assumir que podem interpretar diferentes papéis nos EUA, atrizes e atores brasileiras/os estão, no limite, supondo que: 1) suas habilidades artísticas lhes facultam expressar personagens também em outras realidades culturais; e 2) os repertórios sociais entre Brasil e EUA não são tão distantes a ponto de impedirem o ofício - nesses termos, histórias de amor, ódio, traição e assim por diante, seriam, por definição, "universais".

$\mathrm{Na}$ prática, o desafio foi perseguir, a partir de falas e ações, as expectativas que esses sujeitos possuíam. Ouvindo as gravações das entrevistas repetidas vezes anotamos entonações e silêncios. Prestamos particular atenção à seleção das palavras, à organização das frases e à orquestração do pensamento. $\mathrm{O}$ ajuste do olhar para o uso dos termos e suas pequenas inflexões propiciou investigar como artistas formulavam suas trajetórias: narravam, entre outros, sonhos iniciais em contraste com as condições de trabalho e vida experimentadas na nova cidade.

O texto se divide em quatro partes. Na primeira, apresentamos, de forma breve, o perfil dessas/es artistas e os motivos que forneceram o combustível para a viagem. Em seguida, trabalhamos a dimensão temporal que atravessa esse conjunto de narrativas - o processo migratório é experimentado como um evento definidor da trajetória que marca um antes e um depois na carreira e na vida dos sujeitos aqui abordados. Lidamos então com as questões burocráticas experimentadas; os vistos de entrada criam, por exemplo, um 
empecilho legal - e muitas vezes não planejado - para essas pessoas. Por último, apontamos como esses sujeitos acabam por se "descobrir racialmente" nos EUA. Não raro, por lá são classificados como "latinas/os" e segmentados num tipo específico de papel.

\section{Atrizes e atores do Brasil em Nova York - quem são?}

Embora a migração de atrizes e atores para os EUA pareça um ato anômalo e muito excepcional, é preciso salientar que a iniciativa ganhou maior dimensão no início da segunda década do século XXI. A título de exemplo, em 2012, o canal Multishow da televisão a cabo brasileira, produziu um reality show chamado "Dançando na Broadway". Seis jovens atores e atrizes brasileiras/os, mas residentes em Nova York, competiam para saber quem seria a/o artista mais preparada/o para ingressar no mercado do teatro musical daquela cena artística. A cada dia, participantes apresentavam uma música e uma coreografia para um júri composto de profissionais do teatro local. No final de cada episódio, era escolhido/a um vencedor ou uma vencedora. Foram filmados 14 episódios de 30 minutos, todos transmitidos entre 27 de Julho e 16 de Novembro de 2012, nas sextas-feiras, às $21 \mathrm{~h} 30$.

Quando tomamos conhecimento do programa, nos idos de 2015, Bernardo havia recém começado sua pesquisa de doutorado sobre o trânsito de repertórios teatrais entre Nova York e São Paulo. Ficamos intrigados com a coincidência e com o que aquele novo programa poderia sinalizar: um fluxo significativo de artistas imigrantes brasileiros nos EUA capaz de justificar a produção de um reality show a ser exibido em horário nobre das sextas à noite. Decidimos então assuntar mais a questão. Foi nesse contexto também que resolvemos enfrentar a literatura antropológica mais recente, que vem se debruçando sobre o tema das migrações. O material é tão vasto como diverso. Há estudos que abordam as maneiras como migrantes brasileiras/os se inseriram no setor de serviços domésticos e trabalhos informais em países estrangeiros (Assis, 2011; Margolis, 2009; Martins Jr, 2012; Ribeiro, 1999; Sales, 1999). Outros, ainda, tratam dos modos como as mulheres são introduzidas na indústria do sexo (Mayorga, 2006; Piscitelli, 2007a, 2007b; Maia, 2009). Há uma bibliografia que estuda a correlação entre sexualidade, gênero e raça, posicionando a circulação de mulheres em um contexto de fluxos transnacionais de pessoas e mercados (Piscitelli, 2007b; Cabezas, 2010;Togni, 2015). Há também aqueles que tomaram como tema as formas como sujeitos construíam seu dia a dia fora do Brasil com o intuito de refletir sobre a importância dos fluxos migratórios em contextos variados, sem resumi-los a deslocamentos econômicos ou caracterizá-los, apenas e exclusivamente, como "migrantes econômicos" (Rezende, 2009; Dias, 2009; Dias; Martins Jr, 2013).

Muitas dessas reflexões contribuíram para pensar sobre as rotas de atrizes e atores entre cidades. Contudo, essa forma de migração é distinta daquela tradicionalmente estudada pela literatura, na qual brasileiras e brasileiros, embora muitas vezes oriundos de extratos médios urbanos, estão dispostos a cumprir atividades de pouco prestígio social. 
Por exemplo, para restringir a análise aos EUA, os estudos de Assis (2011), Margolis (2009), Ribeiro (1999) e Sales (1999) indicam como brasileiras/os se inserem no setor de serviços domésticos e trabalhos informais desse país.

Para definir as particularidades sociais dessas/es imigrantes, propusemos um diálogo com o estudo de Igor José de Renó Machado (2006) sobre brasileiros em Portugal. O antropólogo lista oito eixos de clivagem que, combinados, afetariam a experiência de migrantes. São eles: 1) classe; 2) temporalidade da imigração;3) gênero e sexualidade; 4) ascendência; 5) cor/raça; 6) ocupação no mercado de trabalho; 7) origem regional no país de origem; e 8) religião. Fazemos aqui, então, uma breve reflexão tentando levar em conta alguns desses eixos para a análise.

No caso de artistas que viajam para se tornar profissionais do teatro, a maior ambição são os postos ocupados pelos próprios cidadãos americanos: os holofotes, a atenção e os aplausos. Esses sujeitos não operam com o tripé "trabalhar/acumular/retornar", identificado por Dias e Martins Jr. (2013). As ambições parecem conversar com uma gramática diversa que envolve sonho, estudo, trabalho e sucesso. Diferentemente das brasileiras e dos brasileiros presentes no texto de Margolis $(1994 ; 2009)^{4}$, na etnografia e nas entrevistas, a invisibilidade não parece ser uma posição desejável. Entrar no mercado de entretenimento é ambicionar visibilidade. Pleiteando espaço, essas/es artistas precisam operar um novo patamar no jogo de representações: alguns/mas tinham a ambição de poder desempenhar qualquer papel e evidenciar a extensão de sua capacidade interpretativa; já outras/os, percebiam-se marcadas/os por sua origem - classificadas/os como brasileiras/ os ou latinas/os -, o que limitava a variedade das personagens que poderiam executar. Produtores chamam a atenção para as dificuldades que o sotaque cria, diretores de casting insistem em selecionar as atrizes brasileiras para representar somente personagens definidas como "latinas sensuais".

Ao mesmo tempo, essas pessoas dispõem de uma posição econômica e social bastante privilegiada, como declara Oscar:

Eu não sei se é fato, mas aqui em Nova York tem dois núcleos de brasileiros que são diferentes [...]. O pessoal das artes, que se conhece. É o pessoal que tem grana e que quer morar aqui e que os pais bancam. E o pessoal que veio ilegal e que vive outra vida. Que veio para fugir do Brasil. [...] Eles são preocupados em construir a vida deles aqui. [...] Eu tenho convicção de que sou privilegiado, eu conheço pessoas que fizeram faculdade aqui, que não são ricos, que que tiveram outro tipo de educação. Mesmo em Nova York eu estou dentro de uma bolha seletiva. Outros brasileiros talvez tenham outra experiência com isso (Oscar, 27 anos, 2015) .

4 Nos dois estudos realizados por Maxine Margolis - em 1994 e 2009 - brasileiras e brasileiros costumavam considerar sua vida nos EUA como temporária, negando a própria categoria imigrantes. Dada a natureza transitória e incerta de sua residência, tentavam se manter invisíveis e, por isso eram dificeis de serem contabilizados por dados oficiais do Estados Unidos.

Os nomes de artistas mencionados no artigo são fictícios. 
Ojovem ator nomeia como "pessoal das artes” o grupo que experimenta uma trajetória similar a sua - com "grana", "ajuda financeira dos pais" e que buscavam "educação". Os demais, "preocupados em construir uma vida", são classificados como "pessoal que veio ilegal" ". Em seus termos, o primeiro grupo representa um seleto conjunto de intérpretes que pertence, na sua grande maioria, aos extratos médios urbanos de grandes centros metropolitanos do Brasil. Ingressaram nos Estados Unidos com um visto de estudante com o objetivo de frequentar um curso de teatro no país, ambicionando qualificar-se nas técnicas de interpretação, dança e canto. Nota-se como de início já dominam o inglês como idioma. Apenas posteriormente estendem a estadia e batalham pela obtenção do visto de trabalho ou mesmo o green card $^{7}$. Dentre as/os entrevistadas/os, chama a atenção o fato de ninguém se arrepender da mudança e das escolhas de vida que as/os levaram a esse destino. Muitas delas/les já se conheciam, mas não necessariamente conviviam ou eram amigas e amigos.

No total, foram seis mulheres e cinco homens entrevistadas/os. O número pode ser sinal de uma quantidade restrita de intérpretes brasileiros residentes em Manhattan ou, ainda, a evidência da seleção de um grupo específico e razoavelmente homogêneo. Consideramos que as duas hipóteses não são excludentes. Aliás, tal registro não pode ser destacado do contexto econômico e político do país nesse momento ${ }^{8}$, como também o fato de que esse tipo de migração é, em si, privilégio de estratos econômicos médios e altos que podem investir (em dólar) na carreira de suas/seus filhas/os. Trata-se, inclusive de uma carreira que, segundo as/os próprias/os entrevistadas/os, não assegura estabilidade financeira a quem a persegue. Notável o suporte material que a maioria obteve dos pais; salvo três, todos os demais dependiam - em maior ou menor grau - financeiramente da família para pagar algumas contas. Valiam-se dessas suas relações, sobretudo, para o financiamento dos cursos e o aluguel na cidade. Somente com esses recursos econômicos e disponibilidade de tempo esses sujeitos conseguiriam superar as burocracias legais e assegurar o prolongamento de sua estadia.

Importante salientar que entre essas/es artistas, a migração aparece como um projeto individual. A viagem é feita de maneira solitária, sem a supervisão ou a companhia de

6 Os estudos recentes sobre migração são cautelosos no que diz respeito a palavra "ilegal". Normalmente aparece nas falas de sujeitos, mas não como categoria analítica. "Ilegalidade" é um termo cunhado dentro do arsenal gramatical jurídico que formata uma determinada condição com o Estado. Assumi-la como categoria analítica em um trabalho antropológico limita as potencialidades de interpretação que podem ser lançadas aos sujeitos e suas práticas. Para saber mais sobre as implicações epistemológicas, políticas e éticas da categoria, conferir De Genova (2002).

7 Tipo de visto concedido pelas autoridades dos Estados Unidos. O nome oficial é United States Permanent Resident Card (Cartão de Residência Permanente nos Estados Unidos). Diferentemente dos outros tipos de vistos, o green card assegura mais direitos ao migrante que o possui, não expira e classifica o sujeito que o possui como residente permanente.

8 Entre setembro e dezembro de 2015 - período no qual a maior parte das entrevistas ocorreu - o Real desvalorizou-se consideravelmente em relação ao Dólar. Sobretudo a partir de julho de 2015, a moeda nacional saltou do patamar de $\mathrm{R} \$ 3,00$ por dólar para o patamar de $\mathrm{R} \$ 3,75$ por dólar. 
familiares. O motivo, segundo eles, é um “sonho”. Para realizá-lo, inscrevem-se em um curso de teatro e fazem o esforço para finalizá-lo. Embora a família ofereça suporte financeiro, esses sujeitos constroem o discurso valorizando seu investimento pessoal entendem-se como indivíduos que ambicionam superar barreiras e fronteiras para alcançar uma posição privilegiada em um centro hegemônico cultural e economicamente. É, portanto, uma migração distinta daquelas estudadas por Fusco (2007) ou Assis (2011) nas quais as/os migrantes dispõem de uma "rede solidária" para ajudá-los, e que oferece suporte afetivo e, por vezes, financeiro para migrantes em novas terras. Já no caso dessas/es artistas entrevistadas/os, elas/eles não dispunham da mesma situação; os cursos de teatro em que se inscreveram apareciam como os principais catalizadores de suas relações de sociabilidade. Reclamações sobre solidão eram comuns.

Quanto à seleção de pessoas para a entrevista, Bernardo entrou em contato com uma conhecida dele que havia se mudado para Nova York para fazer um curso de teatro. Em uma conversa informal - ela pediu para não ser uma entrevista - contou um pouco de sua vida e passou e-mail e endereço das redes sociais de artistas brasileiras/os que conhecia. Entramos em contato com essas pessoas e marcamos os encontros. $\mathrm{Na}$ medida em que realizávamos as conversas, novas sugestões emergiam. A rede se ampliou e entrevistamos praticamente todos os sujeitos indicados - salvo aqueles que não responderam ou desmarcaram as conversas.

Dentre as pessoas selecionadas, a mais nova possuía 18 anos no momento da entrevista e a mais velha 35. A maior parte - sete - possuía entre 20 e 30 anos. Somente uma morava há mais de 15 anos na cidade. Todas as demais haviam entrado no país nos últimos 5 anos, e apenas uma delas residia há menos de um ano em terras estrangeiras (justamente o mais jovem, de 18 anos). Aquelas/es que haviam migrado há mais de cinco anos, concluíram seus cursos de especialização (que duram, em média 2 a 3 anos) e insistiram no mercado nova-iorquino para obter trabalho e garantir o visto de permanência. Talvez a ausência de pessoas acima de 35 anos revele que há um limite etário na perseguição desse "sonho". Dentre os sujeitos que afirmaram não depender financeiramente dos pais em nenhum aspecto estão, justamente, um homem de 35 anos e uma mulher de 29. Oriundos, inclusive, de famílias que possuem recursos financeiros mais escassos.

Desses migrantes, somente dois não eram provenientes da região Sudeste do país (um era de Porto Alegre e outro de Brasília). Do total, sete haviam nascido no Estado de São Paulo; mais da metade. Destacamos, ainda, que as origens não correspondiam àquelas estudadas por Assis (1999) e Fusco (2007) - a saber, o fluxo de naturais de Governador Valadares (MG) e Criciúma (SC) para os EUA.

No que diz respeito à experiência escolar, um deles ingressou no ensino superior; três não terminaram os cursos que começaram; dois completaram um curso de cinema em escolas particulares no Brasil; três finalizaram cursos que não estavam relacionados à esfera artística; e três ingressaram em departamentos universitários nos EUA, todos ligados às artes (uma em cinema e outros dois em Musical Theater). 
Existem ainda outras diferenças referentes ao tratamento que esses indivíduos receberam nos EUA, a forma como foram percebidas/os, a maneira como se posicionavam e as frustrações a respeito dos limites de seus corpos - marcados por "raça" e gênero. Embora possam ser agrupadas sob o guarda-chuva "pessoal das artes", essas mesmas pessoas ouviram (ou não) diferentes comentários a respeitos de sua nacionalidade e de seus corpos. No trânsito entre as cidades de origem e Nova York, algumas diferenças se fizeram presentes e outras continuaram silenciadas, vamos a elas ${ }^{9}$.

\section{Entre a expectativa e a materialidade: o tempo}

Relatos migratórios mobilizam recursos temporais em abundância. São projeções de futuro, retóricas com justificativas do presente indicando motivos no passado, traços de nostalgia da cidade natal e assim por diante. Nesta sessão, investigamos como interlocutoras/es contavam suas biografias, atentos para a dimensão temporal. Notamos o zelo despendido para equilibrar o hiato entre as expectativas forjadas no Brasil e as experiências em Nova York $^{10}$.

Com seis anos eu assisti Cats $^{11}$, sentada na sala. Eu falei para minha mãe que eu precisava mudar para Nova York. Minha mãe até deu uma entrevista para um jornal [...]. E essa história eu não lembrava, ai eu lembrei quando eu li; quando ela contou. Eu tinha seis anos, eu estava assistindo Cats e eu virei para minha mãe e eu disse: 'mãe, eu preciso ir para Nova York'. E ai ela disse 'que isso menina?' [...]. Aí eu respondi 'Não mãe, é que eu preciso ir para lá porque eu preciso ser essa gatinha'. Que era a gata branca que é a bailarina.E aí ela me colocou no jazz porque eu queria ser bailarina. E aí desde pequena eu falo que quero ser magalina (sic). E por isso que minha mãe me chama de 'magalina' até hoje (Anita, 29 anos, 2015).

Anita é atriz e mora nos EUA desde 2011. Na época, residia no Harlem, dividindo o apartamento com o namorado. Nascida no interior de Minas Gerais, mudou-se para a capital paulista depois de completar o ensino médio, e foi cursar arquitetura em uma faculdade particular. Ingressou então em uma escola de teatro para profissionalização e começou a trabalhar em peças musicais na cidade.

$\mathrm{Na}$ entrevista, narrou como seu projeto era antigo, remontava à infância, à uma memória longínqua e em parte esquecida. Foi a mãe quem contou a versão da "gata" para uma jornalista, em 2012; uma matéria que realizava um balanço sobre a carreira da atriz. Impossível confirmar a veracidade do fato. Mas ela pouco importa, os efeitos e significados da narrativa são, em si, importantes para essa reflexão.Talvez o objetivo da mãe, ao lhe contar

9 Por motivo de limite de espaço, não abordaremos todas as trajetórias estudadas.

10 Estamos aqui inspirado nas sugestões de Sales (1999) que se dedica a uma leitura atenta para as dimensões temporais de migrantes.

11 Musical produzido por Cameron Mackintosh em 1981 em Londres. 
o evento, fosse criar uma continuidade na trajetória da filha, produzindo assim uma narrativa de sucesso: o sonho infantil de ir para Nova York e se tornar bailarina teria se realizado.

Mais à frente na entrevista, Anita explicitou qual foi o evento decisivo para começar seu projeto migratório. Durante o ensaio de uma grande peça de teatro profissional, em 2010, o diretor americano - responsável pela produção - lhe disse:"-você tinha que estar lá". "- Foi um dia que eu apresentei ele para minha mãe. Minha mãe foi ao ensaio e aí ele falou para minha mãe, em inglês, que eu deveria estar aqui porque eles estavam fazendo audição. Minha mãe falou 'o que que ele está falando?'. Eu falei, 'mãe, ele tá falando que eu tinha que estar lá' e ela 'ele vai te levar?’. E aí eu falei para ele: ‘- minha mãe está perguntando se você vai me levar' e ele respondeu '-se você estivesse lá"”. A partir desse momento, Anita começou a juntar dinheiro para a viagem. Um ano depois, embarcou para Nova York e vive na cidade desde então.

Inquietos com os usos da temporalidade nessas narrativas, decidimos - como procedimento metodológico - grifar somente as passagens nas quais a atriz fazia referência ao passado, ao presente e ao futuro. Sob esse filtro, as tessituras temporais cosidas por Anita adquiriram relevância. Se colocarmos os acontecimentos evocados por ela em ordem cronológica notaremos uma coerência histórica nas suas escolhas. Primeiro, o seu desejo infantil de morar em Nova York para fazer a gatinha de Cats, depois o convite do diretor americano e, por último, a vida na grande cidade. Podemos, por outro lado, atentar para a cronologia de seu próprio relato: a sugestão do diretor americano, em 2010, antecedeu a lembrança da mãe de Anita, em 2012 - a história da "magalina” foi recordada somente um ano depois da atriz chegar em Nova York, em 2011. Sem ambicionar escolher uma sequência em detrimento da outra, ambas evidenciam como o esforço para retomar ao passado produz uma potente explicação.

A fala de Anita constitui uma espécie de biografia pregressa, uma justificativa presente e uma projeção futura. A própria estrutura de entrevista parece indicar a criação de uma unicidade, uma trajetória contínua, conforme pondera Schwarcz (2013).Vale a pena, porém, questionar a tendência a construir uma biografia pautada na mera causalidade sequencial - segundo Bourdieu (1996), sujeitos costumam atribuir sentido coerente às suas ações e escolhas. No caso de Anita, parecia importante oferecer um relato biográfico em sequência alinhada de acontecimentos encadeados. A substância motivadora que lhe alimentava era um "sonho" de dançar. Essa expectativa operava ora como combustível para as ações, ora como cola que aglutinava em sequência os fatos que justificavam a vida e as condições que tinha em Nova York.

Quando chegou, a atriz acreditava conseguir facilmente um emprego na Broadway, “achava que as pessoas iam ficar loucas por mim". As expectativas sobre seu futuro eram bastante altas. "Eu vim para Nova York achando que ia ser tudo muito incrível, tudo muito fácil, porque: 'Nova York é o lugar, Nova York é fantástico'. Eu achei que eu ia estar super trabalhando porque as pessoas que eu conheci que vieram para cá ganharam muito dinheiro". A fantasia de vida e sucesso na cidade catalisou suas economias, inspirações e resultou em uma migração. 
Pode-se dizer que um discurso sobre sucesso em Nova York foi atualizado no corpo de Anita. A atriz projetava para o futuro uma série de sinais sobre a cidade que havia acumulado anteriormente. Segundo a socióloga Barbara Adam (2004), a capacidade de projeção do futuro tem papel tão importante quanto a execução da reconstrução de um passado. Sujeitos atuam como profetas e projetistas de suas próprias trajetórias: planejam férias, marcam encontros, imaginam planos para o ano seguinte e afins. Em suas projeções, Anita "colonizava seu futuro" 12 , isto é, tentava apaziguar possíveis angústias e incertezas. Ao comparar sua trajetória com as de outras pessoas que "ganharam muito dinheiro" em Nova York ela convocava o "sonho" - o desconhecido - para seu domínio; transformava o risco em matéria passível de ser administrada.

Após as primeiras experiências ela acabou, porém, por reavaliar sua estada: "Nova York tem mais ou menos 300.000 Anitas. [...] Mentira gente. Mentiram para mim [...]". O impacto experimentado não diz respeito somente ao deslocamento espacial e às novas condições em que se encontrava, mas também à percepção de que seus cálculos e especulações sobre Nova York estavam, de alguma forma, desterradas. Embora seu sonho constituísse a força de combustão, as condições materiais se impuseram e reordenam suas expectativas e decisões. A promessa da cidade dos sonhos, ou dos sonhos na cidade, foi percebida emocionalmente com altas doses de mentira e dor.

Nos primeiros anos de estada, a atriz precisou dividir o quarto com um amigo seu, que também atuava como ator. "É muito caro morar aqui”, afirmou. "É muito caro fazer aula, que é o que eu vim fazer". Matriculada em um curso de pós-graduação de dança para estudantes internacionais, a meta de Anita era se especializar como bailarina. O dinheiro guardado pagava o curso e a passagem de ida, o restante precisaria arrecadar trabalhando. Após constatar a existência de outras "300.000 Anitas", decidiu fazer testes. Também investiu em aulas de canto para melhorar o tom de sua voz.

O presente lhe exigia respostas rápidas e eficazes e, ao mesmo tempo, precisava ser fruído de forma prazerosa. Em sua narrativa pessoal, Anita salienta como batalhara para conseguir estar em um local considerado prestigioso. Sacrifícios, infortúnios e dificuldades eram justificáveis. A retórica revela um tom de fiscalização da felicidade, como se fosse "obrigada" a desfrutar com absoluta satisfação a cidade e a vida que escolhera. Não por coincidência,Anita deixou clara sua angústia:"Toda vez que eu fico desesperada eu penso 'que que eu tô fazendo aqui, porque que eu vim para cá, cara? Eu já tinha tanta coisa lá [no Brasil]'". No país de origem, vinha trabalhando com diretores e produtoras de teatro, reconhecidos, embora não tivesse alcançado uma posição de destaque nas peças. Mesmo assim, ao que tudo indica, imaginava para si um caminho ascendente na carreira. Em seguida, completou em tom de esperança: "Parece que eu desci um degrau, mas esse degrau que eu desci é só para eu subir mais três".

Ao evocar a vida pregressa, de maneira levemente nostálgica, Anita questiona sua experiência migratória. Segundo a pesquisadora Svetlana Boym (2001), é possível sentir

12 Termo cunhado por Adam (2004). 
nostalgia diante das expectativas que se constrói sobre o futuro. Isto é, segundo ela, é possível que uma pessoa sinta nostalgia do passado não como ele foi, mas sim, da forma como ele poderia ter sido. A nosso ver, Anita parece experimentar três tipos de nostalgia: de um lado, sentia falta da posição que ocupava na época em que saiu do país; de outro, imaginava um caminho ascendente em São Paulo, idealizando a cidade do passado como o local que poderia alavancar a carreira, caso tivesse ficado; e, por último, de forma menos evidente, parecia melancólica em relação às fantasias e potencialidades que o futuro lhe reservava - antes da viagem. Nova York era, em sonho, muito mais promissora do que aquela que encontrou ao chegar.

Nesta sessão, exploramos a narrativa de uma única atriz a fim de investigar diversas nuances de seu discurso. Ao atentar para sua retórica temporal, pretendemos grifar como na experiência migratória, passado, presente e futuro são manuseados a fim de orquestrar uma trajetória de si. Isso não impede, porém, a ambivalência de conviver com a frustração e a dor. Entre um plano inicial e sua confirmação final há um empenho discursivo que busca manter o projeto migratório de pé. Na próxima parte, analisamos como as travas burocráticas acabam sendo decisivas no destino dessas/esses artistas. Recorremos aqui a uma narrativa mais plural, mobilizando o discurso de diversas pessoas envolvidas nesse tipo de cena.

\section{Entre a fantasia e a burocracia: os vistos}

Prestes a viajar,Vitor não parecia tão otimista quanto Anita. Sabia que "iria começar do zero". "Eu estava simplesmente deixando de lado toda a minha carreira que já estava em um patamar bacana. E eu já sabia. Mas aqui descobri que era começar do zero, mas começar do zero com coisas contra". Em 2015, data da entrevista, o ator completou 31 anos. Natural de uma grande cidade do interior de São Paulo, o pai de Vitor é advogado e contador, e a mãe trabalhou como professora e, depois, tornou-se psicóloga. Com vasta carreira no Brasil, o ator trabalhou com importantes companhias teatrais em São Paulo e também fez papéis de destaque em uma emissora de TV que produzia novelas. Segundo ele, recebeu uma "ducha de água fria” ao chegar.

Em quase todas as entrevistas realizadas, os vistos para permanência e trabalho no local eram mencionados como fatores de incerteza, dificuldade e angústia. Várias pessoas entrevistadas contavam, com detalhes, quais os tipos de visto que tinham e quais seriam aqueles que planejavam pleitear quando a validade expirasse. Explicavam como, inicialmente, contentavam-se apenas com visto de estudante, mas que as ambições mudavam na medida em que adequavam suas projeções ${ }^{13}$.Vitor comentava, por exemplo, sobre suas altas expectativas: iria estudar primeiro e depois pleitear o OPT (Optional Practical Training), um visto que permite o/a não cidadão/ã americano/a trabalhar por um ano no país após ter se formado em algum curso. Com esse documento em mãos, o rapaz

13 Tal como salientam Dias e Martins Jr. (2013), há um constante processo de reformulação dos projetos migratórios de sujeitos de modo que o prolongamento da permanência é uma alternativa sempre presente. Avalia-se reiteradamente o tempo de estadia e a possibilidade do retorno. 
planejava fazer testes e, aos poucos, obter papéis, contatos e outras oportunidades afins. "Na minha expectativa, eu ia chegar aqui como brasileiro, estudar, me aprimorar. E ter oportunidades e poder concorrer igualmente com os americanos e com os estrangeiros aqui. Mas a primeira coisa que foi frustrante... quando eu cheguei me falaram, o diretor de um escritório de desenvolvimento profissional: 'artista estrangeiro, se não tem o green card, não consegue trabalhar"'. A metáfora da ducha sinaliza o esmorecimento da expectativa inicial. As fantasias parecem ter, por contraste, outra temperatura: são quentes e com propriedades combustivas.

Com essa informação em mãos, o jovem ator decidiu continuar no país até finalizar o estudo. Nutria ainda uma esperança; além do green card haveria uma segunda alternativa: o O1. Um visto de trabalho exclusivamente para trabalhadores com "habilidades extraordinárias" nas áreas de ciências, artes, educação, negócios, atletismo ou "feitos extraordinários" na produção de televisão e filmes. Para obtê-lo, ainda conforme Vitor, um agente especializado em artistas precisaria patrociná-lo; isto é, declarar ao governo estadunidense que gostaria de contratar o artista por sua capacidade, tornando-se responsável por sua pessoa. Entretanto, as grandes emissoras não costumam contratar atores nesse tipo de situação, haveria riscos legais indesejados no processo. $\mathrm{O}$ cenário não era, portanto, muito promissor, mas Vitor não queria desistir. Luan tampouco.

Com 35 anos em 2015, Luan trabalhava há alguns anos no mercado teatral de São Paulo. Embora tenha nascido em Porto Alegre, mudou-se ainda adolescente para a capital paulista com a intensão de se formar como ator e permanecer na cidade. Migrou para Nova York em 2014 e, na época da entrevista, fazia escola de inglês para dispor do visto de estudante. Quando perguntado sobre se a empreitada da viagem teria valido a pena, ele respondeu: "Sempre vale, eu acho que estou só no começo. Ainda não aconteceu o que eu quero. Eu estou só no começo. Meu visto de trabalho vai sair. Aos poucos eu estou construindo essa trajetória que eu acho que vai longe. Eu quero que vá. Eu espero que vá (risos)".

A frase final revela como o ator anuncia uma projeção - "acho"-, salta para um desejo - "quero" - e termina com uma esperança que vem acompanhada com uma espécie de pedido - "espero". Seu projeto de futuro envolvia, porém, a estabilização de sua situação burocrática. O próximo passo seria obter o desejado O1. Para tal, Luan contratou um advogado, e ao longo de 6 meses levantou documentos que comprovassem ao governo dos EUA que: primeiro, era ator; segundo, tinha uma "carreira sólida"; e terceiro, teria algo a "oferecer aos americanos". "Não basta ser ator e querer trabalhar nos Estados Unidos. Não, você tem que provar que os americanos precisam de você e que o que você tem nenhum outro americano pode oferecer". O processo foi complexo. Luan precisou recolher cartas de cidadãos americanos declarando o desejo de empregá-lo; teve que anexar um cronograma de trabalho e dispor de referências de conhecidos do Brasil que haviam trabalhado com ele. Precisava que essas cartas de recomendação declarassem atestados do tipo: "o Luan é um cara incrível porque ele faz isso, faz aquilo, faz aquilo outro. Ele é um exemplo de profissional... enfim". Era imperativo também incluir em seu portfólio todo o material de imprensa na qual estariam grifados as citações ao seu nome. Na época de nossa entrevista, 
fazia uma semana que ele enviara todo o material, e em três meses receberia a resposta. Enquanto isso, Joana, uma colega de trabalho, já dispunha do O1.

A atriz tinha 21 anos quando se mudou para Nova York. Na época da entrevista, Joana estava com 25. Pretendia fazer um curso profissionalizante de teatro de 2 anos, mas acabou permanecendo na cidade após o término do programa, com a firme intenção de seguir trabalhando na área. Com o OPT em mãos e ciente de que ele tinha prazo de validade de um ano, decidiu manter-se por mais tempo na cidade. Como era jovem, não dispunha de um vasto currículo - como Luan, por exemplo -, precisou correr com a burocracia. “Tinha que fazer o máximo de atuação possível, para aplicar para o O1. Então, nesse 1 ano de OPT eu fiz muita coisa (risos)". Na entrevista, a atriz listou alguns de seus trabalhos: foram dois musicais em pequenos teatros com menos de 100 lugares, oito straight play ${ }^{14}$, foi figurante em filmes e trabalhou como atriz em uma companhia de peças infantis. Poucas vezes recebeu por seu trabalho. Mas não parecia se importar muito; afinal, a meta não era ganhar dinheiro, mas antes engrossar o currículo de modo a obter o O1 e permanecer no país. Joana lotou um portfólio com cerca de 400 páginas, desembolsou US\$ 3000,00 para pagar um advogado e obteve o almejado visto. Pelos próximos três anos estaria tranquila. Depois desse período, seriam três as opções que ela teria, então, pela frente: aplicar para o green card - segundo seus cálculos ainda impossível -, casar com alguém - o que estava fora de cogitação - ou renovar o O1. Quando obteve o O1 pela primeira vez, passou escolher quais os trabalhos efetivamente queria fazer.

Mas nem todos conseguem algum tipo de visto. Oscar, mencionado no ínício do artigo, disse ter "bobeado". Após finalizar o curso de teatro de dois anos, percebeu que o prazo para solicitar o OPT havia passado. Como não queria ficar "ilegal” no país, decidiu retornar ao Brasil. "Nos Estados Unidos eles colocam muitas barreiras, só quem quer ficar fica. Eu acho que faço parte do grupo para quem não é tão importante ficar”, declarou. Segundo ele, algumas pessoas faziam tanta questão de ficar em Nova York, e morar fora do Brasil, que o teatro era o que menos importava. Esse não era seu caso. Além disso, seus pais não teriam como bancar mais sua estadia; o mais sensato era voltar. Realizar "bicos" e trabalhar com outras atividades fora da esfera teatral também não faziam parte de seus propósitos.

Diferente de uma parcela de migrantes - para quem o visto é um documento muitas vezes distante do horizonte de possibilidades - as/os artistas entrevistadas/os o consideravam fundamental para sua manutenção no país e a execução de seus trabalhos. Por isso mesmo, dedicavam-se à coleta de documentos, esmeravam-se na contratação de advogados e nas justificativas para obterem a autorização oficial. Suas narrativas detalhadas evidenciam, pois, como a dimensão burocrática mobilizava suas vidas. As falas de Vitor e Luan são especialmente indicativas dos óbices encontrados para obter visto: o documento se transforma em uma barreira, para alguns, intransponível. E não é para menos. $\mathrm{O}$ visto exige os seguintes requisitos: recursos financeiros consideráveis - muitas vezes dos pais -;

14 Classificação na língua inglesa para espetáculos teatrais que usam palavras ditas ao invés de música ou dança para contar uma história. 
artimanhas burocráticas - a contratação de advogados -; tempo para recolher documentos e aguardar a resposta; e a sujeição a trabalhos pouco prestigiosos ou até mesmo não remunerados (como no caso de Joana). O argumento "meritocrático", mobilizado por Vitor durante a entrevista - que dizia que com oportunidades "poderia concorrer igualmente com americanos" -, se desfez ao constatar que nenhuma expectativa resistia aos ataques severos da legislação estadunidense. Mas não só, outras condições nos EUA atravessavam as fantasias cultivadas ainda no Brasil.

\title{
Entre uma personagem e a contratação: gênero e "raça"
}

No mercado do entretenimento, a aparência fenotípica é determinante na seleção dos papéis. Durante as entrevistas ficou evidente como boa parte dos entrevistados e das entrevistadas não calculavam que seriam "racializadas/os"15 na sua experiência migratória. A surpresa dava início a outra frustração:

\begin{abstract}
Quando descobrem que eu sou brasileira eles falam:'então você vai interpretar a latina sexy, certo?' Se você é a brasileira, você vai ser a gostosa da peça. Por exemplo, eu estou trabalhando com dois agentes. E se você vai em uma audição com um agente a primeira coisa que eles perguntam é: 'qual o seu tipo' 'what's your type?'. 'Você é a girl next door, você é a sexy, você é a brava, o que que você é'? 'Cara, não sei. Eu sou Joana, atriz, pronta para qualquer coisa que você me jogar. Mas se for pensar eu tenho facilidade com cenas mais fortes eu posso ser brava muito fácil'. 'Mas você tem sotaque, de onde você é?' 'Brasil'. 'Ah, OK. Então você definitivamente pode interpretar a latina sexy"' (Joana, 25 anos, 2015).
\end{abstract}

No relato acima, a nacionalidade da atriz foi rapidamente sequestrada e transformada em sinônimo de figura erótica. $\mathrm{O}$ sotaque marcou a jovem de forma decisiva. $\mathrm{O}$ certo é que nos Estados Unidos peças de teatro e filmes mobilizam convenções estéticas historicamente construídas - que compõem repertórios sobre como "interpretar a latinidade". No livro Latin Numbers (2015), o pesquisador Brian Herrera reconstrói como, ao longo do século XX, performances "latinas" se transformaram num expediente através do qual se podia ensaiar a racialização de certas pessoas e grupos e, ao fazê-lo, contribuíase para consolidar uma normativa "branco-americana".

Pode-se dizer que as expectativas de diretores e produtores a respeito do corpo de Joana estão em diálogo com o que Piscitelli (2007a, p. 23) chamou de "convenções de erotização". Atributos como o sotaque, os cabelos, as silhuetas e os traços faciais são percebidos de tal maneira que acionam, muitas vezes, repostas eróticas por parte de estrangeiros. Nesse caso, os agentes prescindiram dos traços fisionômicos; o fato de ser

15 A discussão sobre o uso de "raça" e "cor" é espinhosa e repleta de interpretações diferentes. Sobre o debate, verificar, entre outros, Fry (1996), Schwarcz (1998), Sansone (2007), Guimarães (2008) e Moutinho (2004). 
uma mulher brasileira, e ter sotaque, eram assumidos como elementos que conferiam a Joana uma essência sensual.

A atriz continua em seu relato: "[por exemplo] tem três papéis, uma é a menina que tem que seduzir não sei quem. 'Ah, Joana is for that', 'Ué, por quê?' 'Porque você tem o seu charme brasileiro, você sabe como fazer isso"”. Como mulher, sua nacionalidade foi projetada em termos "raciais" - essencializados e substancializados - cujos significados revelariam um estoque de "erotismo inerente". No entanto, o aparente elogio a sua sensualidade é recebido por ela com altas doses de incômodo. Segundo Joana, tais classificações estariam em desacordo com sua personalidade - "Se você olhar para mim, eu não sou a 'sexy latina'. Eu sou uma menina ' $x$ ', sou uma teenager'.

No Brasil ela se percebia e era percebida como branca. Uma combinação de fatores pode explicar essa autorrepresentação. De um lado, a posição social que ocupava participar dos estratos econômicos mais elevados, morar em grandes centros urbanos e em uma família detentora de capital econômico, cultural e social - garantia a ela um certo embraquecimento. Além disso, na classificação informal de pigmentos no Brasil, suas características fenotípicas - cabelos lisos, nariz mais afinado - adicionavam mais elementos na percepção de que ela era definitivamente "branca"16.

Dessa forma, a racialização experimentada nos EUA era entendida como uma restrição e um rebaixamento. Diferente do Brasil, ela não poderia transitar da forma como estava acostumada. Por outro lado, as classificações a ela atribuídas soavam como uma séria limitação às suas potencialidades interpretativas. Afinal de contas, a atriz sentiase "pronta para qualquer coisa" - poderia ser brava, fazer cenas fortes e outras variações. Se no Brasil o leque de personagens disponíveis parecia ser amplo, já nos EUA Joana notou que os papéis disponíveis para as latinas costumavam ser secundários e menos prestigiosos. Ao invés de alargar seu horizonte, como parecia ser o plano inicial, viu, assim, um claro encurtamento nas suas escolhas. Anita, por sua vez, relatou experiência diferente:

Desde o Brasil eu nunca tive uma classificação certa. Não certa... Uma classificação só. No Hairspray ${ }^{17}$ eu era cover de todas as meninas. No Hairspray tinha elenco branco e elenco negro e eu era cover de todas elas. Então, às vezes no mesmo espetáculo, eu começava como uma menina branca, no meio eu tirava a maquiagem, colocava um make escuro e virava negra, depois virava branca no mesmo espetáculo. Tiveram alguns espetáculos que eu fiz branca e negra no mesmo espetáculo. Então aqui [nos EUA], eu não sou branca, isso é uma certeza, não sou "caucasian". Mas eu posso ser negra, eu posso ser indiana, posso ser latina. Tudo depende do cabelo. Depende da peruca. Se eu tenho uma peruca enrolada eu sou negra, se eu tenho uma peruca lisa eu sou indiana ou latina. Então quando eu chego, sempre tem um pescoço para o lado [com uma expressão de indagação]: 'o que ela é?'.

16 Para saber mais sobre o assunto, conferir Norvell (2001).

17 No Brasil, Anita participou da montagem do musical Hairspray, em 2010, em São Paulo. Na ocasião, ela fazia parte do coro e trabalhava como substituta (cover) para caso alguma atriz faltasse nos dias do espetáculo. 
Quando eu falava que eu era negra no Brasil as pessoas falavam, 'você não é negra' (Anita, 25 anos, 2015).

No Brasil, a "cor" de Anita não parecia lhe impor limites; muito pelo contrário, podia fazer parte de um elenco tanto "branco" quando "negro". Para ela, "cor" representava um contínuo estado de negociação (Schwarcz, 1998). Ao contrário de Joana, mesmo nos EUA, Anita parece experimentar alguma fluidez nas classificações: ser "caucasiana" não faz parte de suas possibilidades, entretanto, "dependendo da peruca", ela poderia transitar em um lugar ou em outro ${ }^{18}$. Matéria disponível ao manejo, o cabelo ou a peruca podem ser formas de produção de representações estéticas variadas (Figueiredo, 2002; Mizrahi, 2015). A plasticidade dos cabelos permite um leque de possibilidades para as apresentações que, longe de serem fixas, são manobradas por sujeitos, especialmente por mulheres.

Assim, Anita não descreveu sua racialização nos EUA como sinônimo de restrição. Mesmo no Brasil, nessa complicada régua da "cor social" ela parecia negociar e burlar (dentro de limites, certamente) as classificações sociais a ela exteriormente atribuídas. O deslocamento migratório não acrescentou um novo tipo de empecilho. Muito pelo contrário, ela estabeleceu um paralelismo entre o país de origem e o país receptor: em ambos as experiências em termos de gênero e "raça" eram de alguma maneira similares.

Durante toda a entrevista, Vitor não relatou qualquer circunstância em que tenha se sentido estigmatizado por ser brasileiro ou mesmo identificado como "latino". Autoclassificado como "branco", ao longo da conversa também destacou como seus colegas do teatro o chamavam de "galã" - referência ao fato de que fora protagonista numa novela e, portanto, dispunha de atributos físicos que eram com frequência associados à beleza, como os olhos azuis, a pele clara e os cabelos escuros. Durante a entrevista ele explicou que, além do visto, outro obstáculo enfrentado era o seu sotaque. Segundo ele, para fazer qualquer personagem americano é preciso não ter sotaque: "Eu já estou com sotaque bem americanizado e não teria problema para fazer um papel americano, acho que daria para fazer, já, mas é dificil". Dentre seus investimentos, dedicou tempo e recursos às aulas particulares, sempre com o objetivo de diminuir seu sotaque e expressões muito presas ao português. Destacou, ainda, que precisava atentar para a cadência da fala; colocar as palavras corretamente; além de ter conhecimento do sotaque de outras regiões dos EUA e até acentos de outras épocas da história.

18 Beserra (2005) também sugere que a integração diferenciada de migrantes brasileiros/as nos Estados Unidos desafia o mito da rigidez do sistema racial deste país. Ela sinaliza, embora não aprofunde, a ideia de que de acordo com a posição social econômica e o tom da pele, indivíduos ocupam lugares diferentes nos EUA. Uma recente bibliografia sobre o sistema classificatório racial produzida nos EUA indicia como não há "rigidez" nas formas de percepção, especialmente com a entrada de tantos "latinos" no país.Vide Lee e Bean, 2007. 
Curiosamente, o ator explicou que retirava seu sustento em Nova York trabalhando como voice over ${ }^{19}$. Em uma ocasião, ele dublou a voz do jogador de futebol Neymar para uma campanha na Copa de 2014. Quando falava em inglês, seu sotaque estava justificado - afinal Neymar é brasileiro. Além disso, fez a voz de personagens de outros jogos como "Clash of Clans" e "Harry Potter". Nas duas ocasiões, Vitor gravou o áudio em português, no exterior, para um produto que seria vendido no Brasil. Emprestando sua voz para diferentes personagens e campanhas, o corpo de Vitor não estava, porém, em evidência. Sua voz estava dissociada de seu corpo e assim ele encontrou um nicho de mercado bastante singular no qual seu sotaque deixava de ser um problema. Ao mesmo tempo, o prestígio de seu trabalho sofreu uma inflexão - de protagonista de novela a voice over.

Como se vê, chegar nos EUA é, para boa parte dos entrevistados - sobretudo as mulheres entrevistadas - notar-se racializada. Para Joana, quando estava no Brasil a "cor" da pele, a "raça", não se consolidava como sinal diacrítico marcante, já em Nova York viu-se classificada em termos com os quais não se identificava. Para os homens, como é o caso de Vitor, o deslocamento entre cidades (e países) também não afetou sua situação. A posição de migrante brasileiro é menos racializada, sexualizada e marcada por gênero do que a posição das mulheres brasileiras. Não queremos dizer que gênero vem à reboque de "raça", mas apenas sinalizar como fica evidente como não se pode desconsiderar que homens e mulheres experimentam de maneira diversa as suas marcas de racialização.

No segmento de entretenimento, essas/es artistas exercem funções nas quais o corpo não é somente relevante, mas determinante. A título de comparação, os relatos colhidos por Dias (2009) revelam como migrantes brasileiros em Londres exerciam funções nas quais a aparência pessoal não tinha relevância de primeira ordem - a maquiagem não era determinante, os cabelos eram cobertos e as pessoas trajavam uniforme de modo a homogeneizar as silhuetas de trabalhadores. Durante nossas entrevistas, interlocutoras/es recorriam diversas vezes à categoria "perfil" para explicar a relação entre um(a) artista e uma personagem. Sem uma definição precisa, o que se destaca é a combinação de alguns sinais diacríticos: o formato corporal (altura, peso e silhueta), a cor da pele e cabelo, os traços do rosto, o timbre sonoro e até a personalidade são fatores que, combinados, produzem um “perfil”. A relevância do corpo é de primeira ordem para esses sujeitos.

Ao tratar de atrizes e atores brasileiros nos Estados Unidos, podemos lançar luzes para compreender as políticas de representação em vigor no mercado de entretenimento desse país. $\mathrm{O}$ estudo, acreditamos, oferece um acesso privilegiado para as investigações sobre algumas formas de ser brasileira/o nos EUA - tanto do ponto de vista dos sujeitos, quanto do ponto de vista da indústria de entretenimento. Nas trajetórias e discursos que apresentam essas mulheres e homens migrantes vivenciam como o mercado teatral e filmico dos EUA aloca brasileiras/os em um sistema de imaginação. Ao mesmo tempo,

19 Voice over é o nome de uma técnica de produção na qual a voz de um ator ou atriz é gravada e utilizada em programas de rádio, televisão, no cinema, no teatro ou outras formas de apresentação. O trabalho é bastante comum em vídeo games, documentários e anúncios de propaganda. 
esses mesmos sujeitos negociam e burlam restrições, produzindo e tencionando fronteiras sobre os estereótipos que informam os produtores estadunidenses.

\section{Últimas considerações}

O trânsito de artistas entre esses países permitiu investigar como expectativas de sucesso trafegam e criam práticas. É curioso notar de que maneira tal recrutamento opera de forma diferente quando comparado as brasileiras e os brasileiros que se dedicam a trabalhos considerados "subalternos". Como vimos, entre artistas brasileiras/os, está sempre em jogo uma dupla tensão: de um lado, uma espécie de sedução; de outro, uma negação. Anita escuta, como uma melodia, o diretor americano lhe oferecer um trabalho em Nova York. Seu imaginário é então povoado por muitas projeções. Entretanto, logo em seguida, as condições materiais de competição, a racialização e os entraves na burocracia acabam por se impor tal qual aduanas restritivas.

É possível, pois, atentar para a pluralidade de experiências desses sujeitos migrantes. Embora soem homogêneas, analisá-las em conjunto não implica perder de vista dimensões mais microscópicas, que contribuem para pensar como sistemas de classificação, discursos de sedução e impedimentos legais agem no processo de migração e muitas vezes o condicionam.

\section{Referências}

ADAM, Barbara. Memory of the Future. International Society for the Study of Time. Cambridge University, Clare College, July 2004. (Paper presented at ISST Conference). Disponível em: <http://www.cardiff.ac.uk/socsi/ futures/memoryofthefuture.pdf $>$ Acesso em: 20 set. 2017.

APPADURAI, Arjun. Modernity At Large: cultural dimensions of globalization. Minneapolis: University of Minnesota Press, 1996.

ASSIS, Glaucia de Oliveira. Entre dois lugares: as experiências afetivas de mulheres imigrantes brasileiras nos Estados Unidos. In: PISCITELLI, Adriana; ASSIS, Glaucia de Oliveira; OLIVAR, José Miguel Nieto (Org.) Gênero, sexo, afetos e dinheiro: mobilidades transnacionais envolvendo o Brasil. Campinas, São Paulo: Unicamp/ PAGU, 2011.

Estar aqui..., estar lá...: uma cartografia da emigração valadarense para os EUA. In: SALES, Teresa; REIS, Rossana Rocha (Org.). Cenas do Brasil Migrante. São Paulo: Boitempo Editorial, 1999.

BESERRA, Bernadete. From Brazilians to Latinos? Racialization and Latinid in the making of Brazilian Carnival in Los Angeles. Latino Studies, n. 3, p. 53-75, 2005.

BOURDIEU, Pierre. A ilusão biográfica. In: FERREIRA, M. (Org.). Usos e Abusos da história oral. Rio de Janeiro: Editora da Fundação Getúlio Vargas, 1996.

BOYM, Svetlana. The future of nostalgia. USA: Basic Books, 2001.

CABEZAS, Amalia. Economies of Desire, Sex and Tourism in Cuba and the Dominican Republic. Philadelphia:Temple University Press, 2010.

DE GENOVA, Nicholas. Migrant 'illegality' and deportability in everyday life. Annual Review of Anthropology, v. 31, p. 419-447, 2002. 
DIAS, Gustavo Tentoni. O processo de fixação do migrante brasileiro em Londres: a importância das práticas cotidianas na elaboração de sua identidade. Ponto Urbe: revista no núcleo de antropologia urbana da USP [online], n. 4, 2009. Disponível em: <http://pontourbe.revues.org/142>. Acesso em: 17 set. 2017.

DIAS, Gustavo; MARTINS Jr, Angelo. Imigração brasileira contemporânea: discursos e práticas de imigrantes brasileiros em Londres. Análise Social, v. XLVIII, n. 209 (4º), p. 810-832, 2013.

FIGUEIREDO, Ângela. "Cabelo, cabeleira, cabeluda e descabelada": Identidade, consumo e manipulação da aparência entre os negros brasileiros. In: REUNIÃO ANUAL DA ASSOCIAÇÃO NACIONAL DE PÓSGRADUAÇÃO E PESQUISA EM CIÊNCIAS SOCIAIS, XXVI, 2002, Caxambu. Anais... Caxambu:Associação Nacional de Pós-Graduação e Pesquisa em Ciências Sociais, 2002 p. 1-14. Disponível em: < http://www.anpocs. com/index.php/papers-26-encontro/gt-23/gt17-14/4475-afigueiredo-cabelo/file>. Acesso em: 17 set. 2017.

FRY, Peter. O que a Cinderela negra pode dizer sobre a "política racial” no Brasil. Revista USP, São Paulo, n.28, p. 122-135, 1995-1996.

FUSCO,Wilson. Capital social e dinâmica migratória: um estudo sobre brasileiros nos Estados Unidos. Campinas, São Paulo: Núcleo de estudos de População, Unicamp, 2007.

GUIMARÃES, Antonio Sérgio Alfredo. Cor e Raça: raça, cor e outros conceitos analíticos. In. SANSONE, Lívio; PINHO, Osmundo Araújo (Org.). Raça: novas perspectivas antropológicas. 2. ed. rev. Salvador: Associação Brasileira de Antropologia; EDUFBA, 2008.

HERRERA, Brian. Latin Numbers - playing latino in twentieth-century US Popular Performance. Estados Unidos: University of Michigan Press, 2015.

LEE, Jennifer; BEAN, Frank. Reinventing the color line immigration and America's new racial/ethnic divide. Social Forces, v. 86, n. 2, p. 561-568, Dec. 2007. Disponível em: <https://eric.ed.gov/?id=EJ784614>. Acesso em: $01 \mathrm{dez} .2017$.

MACHADO, Igor José de Renó. Imigração em Portugal. Estudos Avançados, v. 20, n. 57, p. 119-135, 2006. <http:// www.revistas.usp.br/eav/article/view/10151/11735>. Acesso em: 30 jul. 2017. http://dx.doi.org/10.1590/ S0103-40142006000200010.

MAIA, Susana. Sedução e identidade nacional: dançarinas eróticas brasileiras no Queens, Nova York. Estudos Feministas, Florianópolis, v. 17, n. 3, p. 769-797, set.dez. 2009. http://dx.doi.org/10.1590/S0104026X2009000300009

MARCUS, George. Ethnography in/of the world system: the emergence of Multi-sited Ethnography. Annual Review of Anthropology, n. 24, p. 95-117, 1995.

MARCUS, George; CLIFFORD, James (Org.). A escrita da cultura: poética e política da etnografia. Tradução Marua Claudia Coelho. Rio de Janeiro: Ed. UERJ; Papéis Selvagens Edições, 2016.

MAR GOLIS, Maxine L. An Invisible minority: Brazilians in New York City. Gainesville, Florida: University Press of Florida, 2009.

Little Brazil:An ethnography of Brazilian Immigrants in New York City. Princeton: Princeton University Press. 1994.

MARTINS JR. Angelo. De cleaner a waiter: trajetórias de trabalhadores brasileiros em Londres. 2012. 149f. Dissertação (Mestrado em Sociologia) - Universidade Federal de São Carlos (UFSCAR), São Carlos, 2012.

MAYORGA, Claudia. Identidade, Migração e Gênero: O caso de mulheres brasileiras prostitutas em Madrid. Anais... Seminário Internacional Fazendo Gênero 7, Santa Catarina, 2006.

MIZRAHI, Mylene. Cabelos ambíguos: beleza, poder de compra e "raça" no Brasil urbano. Revista Brasileira de Ciências Sociais, São Paulo, v. 30, n. 89, p. 31-45, out. 2015. http//dx.doi.org/10.17666/308931-45/2015

MOUTINHO, Laura. Razão, "cor" e desejo: uma análise comparativa sobre relacionamentos afetivo-sexuais "interraciais" no Brasil e na África do Sul. São Paulo: Unesp, 2004. 
NORVELL, John M.A brancura desconfortável das camadas médias brasileiras. In: MAGGIE,Yvone REZENDE, Claudia Barcellos (Org.). Raça como retórica: a construção da diferença. Rio de Janeiro: Civilização Brasileira, 2001.

ORTNER, Sherry. (1984).Teoria na Antropologia desde os anos 60. Mana, v. 17, n. 2, p. 419-466, 2011. Disponível $\mathrm{em}: \quad<$ http://www.scielo.br/scielo.php?script $=$ sci_arttext\&pid $=$ S0104-93132011000200007\&lng $=$ en\&nrm $=\mathrm{i}$ so >. Acesso em: 01 dez. 2017. http://dx.doi.org/10.1590/S0104-93132011000200007.

PISCITELLI, Adriana. Corporalidade em confronto: brasileiras na indústria do sexo na Espanha. Revista Brasileira de Ciências sociais, São Paulo, v. 22, n. 64, jun. 2007a. Disponível em: $<$ http://www.scielo.br/scielo.php?script=sci_ arttext\&pid $=$ S0102-69092007000200002\&lng=en\&nrm=iso>. Acesso em: 01 dez. 2017. http://dx.doi. org/10.1590/S0102-69092007000200002.

. Viagem e Sexo on-line: a internet na geografia do turismo sexual. In: MELO, Hildete Pereira de; PISCITELLI, Adriana; MALUF, Sônia Weidner; PUGA,Vera Lucia (Org.). Olhares Feministas. Brasília: Ministério da Educação; UNESCO, 2007b.

REZENDE, Claudia Barcellos. Retratos do estrangeiro: identidade brasileira, subjetividade e emoção. Rio de Janeiro: Editora FGV, 2009.

RIBEIRO, Gustavo Lins. O que faz o Brasil, Brazil: Jogos Identitários em São Francisco. In: REIS, Rosana Rocha; SALES, Teresa (Org.). Cenas do Brasil Migrante. São Paulo: Boitempo Editorial, 1999.

SALES, Teresa. 'Identidade étnica entre imigrantes brasileiros nos EUA'. In: REIS, Rosana Rocha; SALES, Teresa (Org.). Cenas do Brasil Migrante. São Paulo: Boitempo Editorial, 1999.

SANSONE, Livio. Negritude sem etnicidade: local e o global nas relações raciais e na produção cultural negra do Brasil. Salvador: Edufba; Pallas, 2007.

SCHWARCZ, Lilia Moritz. Biografia como gênero e problema. História Social, n. 24, p. 51-73, 2013.

Nem preto nem branco, muito pelo contrário: cor e raça na intimidade. In: História da Vida Privada IV.

São Paulo: Companhia das Letras, 1998. p. 173-244.

STRATHERN, Marilyn. Partial Connections. Savage, MD: Rowman \& Littlefield, 1991.

TOGNI, Paula. A Europa é o Cacém: Mobilidades, gênero e sexualidade nos deslocamentos de jovens brasileiros para Portugal. 2015. 318f. Tese (Doutorado em Antropologia) - Escola de Ciências Sociais e humanas, Instituto Universitário de Lisboa, Lisboa, 2015. 


\title{
Migrating Dreams: Brazilian actresses and actors in New York
}

\begin{abstract}
In this article we work with middle class young adults Brazilians who traveled to New York, in the United States, with the goal of transforming themselves into artists. Moved by expectations of immersion in the American entertainment market, they migrate with the intention of trying a new career abroad. We are particularly interested in analyzing how these subjects dealt with the gap between the initial expectations and the material conditions experienced. Between the stardom plan and their achievement, they face a competitive market, bureaucratic problems and the instantaneous "racialization" of their bodies - especially among women. We selected the notion of "drop in expectation" - its consequences and effects - as the main object of analysis and took as inspiration what has been called, in the bibliography, as "multi-situational" researches, paying attention to how allegories and dreams circulate between the two cities.
\end{abstract}

Keywords: artists, migration, United States, dreams, drop in expectation.

\section{Sueños que migran: actrices y actores brasileños en Nueva York}

\section{Resumen}

En este artículo trabajamos con las narrativas de jóvenes de clase media brasileña que viajaron a Nueva York, Estados Unidos, en los años 2010, con la intención de especializarse como artistas. Motivados por expectativas de inmersión en el mercado de entretenimiento estadounidense, emigraron con el sueño de emprender una carrera en el exterior. Estamos particularmente interesados en analizar la forma en que estos sujetos se ocupan de la brecha entre las expectativas iniciales y las condiciones materiales experimentadas. Entre el plano de estrellato y su realización, enfrentan un mercado competitivo, obstáculos burocráticos y la instantánea "racialización" de sus cuerpos - especialmente en el caso de las mujeres. Elegimos la noción de "quiebra de expectativas" - sus consecuencias y efectos - como objeto de análisis y buscamos inspiración en lo que se ha convenido llamar de investigaciones "multi-situadas", atentos que estamos a cómo alegorías y sueños transitan entre ciudades

Palabras clave: artistas, migraciones, Los Estados Unidos, sueños, ropimiento de las expectativa. 